\title{
Soft drinks consumption and child behaviour problems: the role of food insecurity and sleep patterns
}

\author{
Christian King*
}

Department of Nutrition and Health Sciences, University of Nebraska - Lincoln, 104I Ruth Leverton Hall, Lincoln, NE 68583, USA

Submitted 9 March 2016: Final revision received 20 June 2016: Accepted 5 July 2016: First published online 30 August 2016

\begin{abstract}
Objective: To examine whether the association between soft drinks consumption and child behaviour problems differs by food security status and sleep patterns in young children.

Design: Cross-sectional observational data from the Fragile Families and Child Wellbeing Study (FFCWS), which collected information on food insecurity, soft drinks consumption, sleep patterns and child behaviour problems. Bivariate and multivariate ordinary least-squares regression analyses predicting child behaviour problems and accounting for socio-economic factors and household characteristics were performed.

Setting: Twenty urban cities in the USA with a population of 200000 or more.

Subjects: Parental interviews of 2829 children who were about 5 years old.

Results: Soft drinks consumption was associated with aggressive behaviours, withdrawn and attention problems for children aged 5 years. However, the association differed by food security status. The association was mostly statistically insignificant among food-secure children after accounting for socio-economic and demographic characteristics. On the other hand, soft drinks consumption was associated with behaviour problems for food-insecure children even after accounting for these factors. However, after accounting for child sleep patterns, the association between soft drinks consumption and child behaviour problems became statistically insignificant for food-insecure children.

Conclusions: The negative association between soft drinks consumption and child behaviour problems could be explained by sleep problems for food-insecure children. Since about $21 \%$ of households with children are food insecure, targeted efforts to reduce food insecurity would help improve dietary (reduce soft drinks consumption) and health behaviours (improve sleep) and reduce child behaviour problems.
\end{abstract}

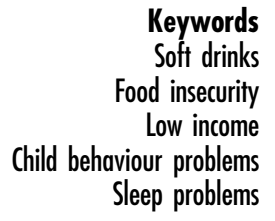
Food insecurity iour problems Sleep problems
Although the consumption of soft drinks in the USA has been on a downward trend, Americans still consumed an average of 157 litres (41.4 gallons) of soft drinks in 2014, down from a high of 200 litres (53 gallons) in $2000^{(1)}$. Between 1999 and 2004, 70\% of children between 2 and 5 years of age consumed soft drinks on any given day and about $11 \%$ of their total daily energy intake came from soft drinks between 1999 and 2004 ${ }^{(2)}$. When considering sugar-sweetened beverages as a whole, however, consumption decreased slightly between 1999 and 2010 (3).

Soft drinks provide little nutritional benefit and are associated with health ailments ${ }^{(4-6)}$. In addition, soft drinks consumption has an association with higher aggressive and emotional behaviour problems in children and adolescents $^{(7,8)}$. A meta-analysis showed that studies with stronger methods and design (such as longitudinal and experimental) found larger negative impacts of soft drinks consumption on nutrition and health ${ }^{(5)}$. Children in lowincome households tend to consume a higher proportion of energy from soft drinks compared with children in higher-income households ${ }^{(9-12)}$.

Food insecurity, which the US Department of Agriculture defines as the inability to access enough food for an active, healthy life ${ }^{(13)}$, has negative consequences on children. The US Department of Agriculture has developed and validated a questionnaire with eighteen items for households with children to measure food insecurity ${ }^{(13)}$. The questionnaire attempts to capture both undernutrition and malnutrition with questions such as whether the children ever skip a meal because there wasn't enough money for food' or whether the parents 'couldn't feed our children a balance meal, because we couldn't afford that'. Several studies have found an association between food insecurity and behaviour problems in children such as 
externalizing behaviours, internalizing behaviours and attention problems ${ }^{(14-17)}$. Undernutrition and malnutrition both contribute to more behaviour problems in children through neurocognitive deficiencies resulting from the lack of nutrients that are essential for child development ${ }^{(17,18)}$. Low-income households are at substantially higher risk of experiencing food insecurity ${ }^{(19)}$. Food-insecure households have low nutrient intakes and nutrient inadequacies ${ }^{(20,21)}$. Children in low-income and food-insecure households have lower consumption of vegetables and fruits ${ }^{(22)}$ and higher consumption of soft drinks ${ }^{(23,24)}$. Low-income households have lower access to supermarkets and are left with convenience stores that provide mostly foods of little nutritional value ${ }^{(25)}$. Given that food insecurity also contributes to child behaviour problems ${ }^{(14-17)}$, there may be a differential relationship between soft drinks consumption and child behaviour problems by food security status.

Two studies have found an association between soft drinks consumption and behaviour problems in children $^{(7,8)}$. The first one used a cross-sectional population-based survey of adolescents in Norway and found that soft drinks consumption is associated with mental distress, hyperactivity and conduct problems ${ }^{(7)}$. The second one used data from the Fragile Families and Child Wellbeing Study (FFCWS) and found that soft drinks consumption increases aggressive behaviours, attention problems and withdrawal behaviour ${ }^{(8)}$. The present study expands on the second study by examining food insecurity as a potential omitted factor that could explain this association.

Not only food insecurity may explain some of the association between soft drinks consumption and child behaviour problems; sleep could be another important omitted variable that is related to both food insecurity and child behaviour problems. Evidence from the literature shows that a lack of sleep or poor sleeping pattern in children is associated with behaviour problems ${ }^{(26-28)}$. In addition, several studies have established that sugarsweetened beverages increase sleep problems and sleep disruptions ${ }^{(29-31)}$, which is hypothesized to be due to caffeine $^{(32-34)}$ and sugar ${ }^{(35)}$. However, there is evidence that food insecurity is associated with poor sleep outcomes $^{(36)}$. As a result, the association between soft drinks consumption and child behaviour problems could be explained by food insecurity and sleep disruption.

The primary objective of the present study was to determine whether the association between soft drinks consumption and child behaviour problems differs by food security status. In addition, the study tested whether sleeping problems could explain some of the association. The study sample is composed of fragile families living in large urban cities to examine child behavioural problems. In addition, the study accounts for potential confounding factors (e.g. parenting, material hardship) that may affect both soft drinks consumption and child well-being.

\section{Methods}

\section{Study population}

The FFCWS sampled 4898 children born between 1998 and 2000 in twenty large cities in the USA with a population greater than 200000 . By design, three-quarters of mothers in this sample at baseline were unmarried as they are at higher risk of living in poverty and being separated from the father. When weighted, the sample is representative of non-marital births in cities of 200000 or greater population ${ }^{(37)}$. All families provided informed consent before participating in the study. Because the Fragile Families data set is publicly available, institutional review board approval was not needed.

The present study focuses on data collected at the 5th year when children were about 5 years old. There were 4055 mothers (85\%) who completed the core survey at the 5th year. Mothers who agreed to be interviewed at home completed a primary caregiver survey and in-home assessments. The analytical sample for the current study includes 2829 mothers (70\%) who completed the in-home survey at year 5, which includes complete information on soft drinks consumption, food security status and child behaviour problems. The analytical sample represents over half (58\%) of the original sample. Comparing the sample before and after attrition (not shown), mothers who dropped out of the sample were less likely to have completed high school, more likely to be Hispanic, have slightly lower household income, less likely to be married and substantially more likely to be separated from the father. Previous studies have examined attrition in this data set and found that the families lost to attrition are at greater disadvantage. As a result, the estimates using the Fragile Families data are either unaffected by attrition or tend to be conservative and would be larger if these families would have remained in the sample ${ }^{(38-40)}$.

\section{Child behaviour problems}

Child behaviours at year 5 were assessed using the Child Behavior Checklist for ages $1 \frac{1 / 2-5}{\text {, a widely used }}$ instrument to measure different aspects of behaviour problems ${ }^{(41,42)}$. Child behaviour problems were constructed using the following measures: aggressive behaviours, withdrawn behaviours and attention problems. The survey is usually completed by the caregiver and asks whether s/he thinks that each statement relating to the behaviour of the child is not true $(=0)$, somewhat or sometimes true $(=1)$, or very true or often true $(=2)$. The child aggressive behaviours measure is constructed from twenty-five questions. The withdrawn subscale is constructed from eight questions, and the attention problems subscale is constructed using nine questions. These measures were standardized according to the age of the children. 


\section{Soft drinks consumption}

Mothers were asked at year 5 how many servings of soft drinks the child has on a typical day, with responses ranging from 0 to 5 or more. Due to the lower number of children having 4 or 5 servings daily, they were grouped into the same category ( $n$ 105). The daily soft drinks consumption measure is a continuous variable from 0 to 4 .

\section{Food insecurity}

Food insecurity was measured using the Food Security Module developed and validated by the US Department of Agriculture, which asked eighteen questions relating to food security during the 5 th year of the study. The questions are ranked in order of severity; if respondents answer negatively to the first few questions, they are likely to be screened out of the questionnaire. The first question asks whether the household head worried whether s/he would run out of food in the last month. The US Department of Agriculture distinguishes between low food security and very low food security. Because few children experienced very low food security in this sample a binary measure of food insecurity was used, which has been similarly done in the literature ${ }^{(43-47)}$. Households with children that answered affirmatively to at least three of these questions were considered food insecure.

\section{Child sleep patterns}

The caregiver answered a few questions related to the sleep patterns of the child; for example, the caregiver reported whether the child has trouble sleeping at night and the number of hours the child sleeps at night. A binary variable indicates whether the child has trouble sleeping at night. As a sensitivity check, the number of hours of sleep the child gets was used instead and the findings were similar.

\section{Other control variables}

Socio-economic and demographic control variables included child's gender, maternal educational attainment (high-school dropout, high-school graduate, some college, or college graduate and beyond), maternal race/ethnicity (white, black, Hispanic or other), income to poverty ratio (continuous variable), number of children and relationship status of parents (married, cohabitating, non-resident or separated). Because parenting characteristics are correlated with food insecurity and child behaviour problems $^{(14)}$, the study controlled for parenting stress and maternal depression. Parenting stress was measured using an average of responses to four questions such as 'Being a parent is harder than I thought it would be'. Responses ranged from strongly disagree $(=1)$ to strongly agree $(=4)$. Maternal depression was constructed using the Composite International Diagnostic Interview Short Form (CIDI-SF ${ }^{(48)}$. Mothers were asked whether they felt depressed for two weeks during the past year or whether they lost interest in pleasurable activities. If they responded affirmatively to at least one of these two questions, they are asked seven more questions such as whether they had trouble sleeping or felt worthless. Mothers who answered affirmatively to three or more were considered at risk of a major depressive episode. Antecedent factors such as whether the mother smoked during pregnancy and low birth weight of the child were included. Other measures of instrumental support included material hardship and the level of social support available to mothers. Material hardship was constructed using responses to five questions such as whether they missed a rent or mortgage payment or whether they missed payment on utilities. Social support was constructed using responses to four questions such as whether mothers could count on someone to lend them money or to provide them with emergency child care. Controls for history of domestic violence and whether one parent had drug or alcohol problems in the past were included. Lastly, the study controlled for maternal and paternal self-control, which can affect child behaviours. These measures were created using four questions such as 'I often say and do things without considering the consequences'.

\section{Statistical analysis}

Several variables in this data set had missing values. Because imputing missing values on the dependent variables is not recommended, these observations were dropped $^{(49)}$. The observations with missing values on the independent variables were imputed using multiple imputed chained equations ${ }^{(50,51)}$. The estimates with and without the missing data provided similar results, so only the imputed ones are presented herein. Bivariate and multivariate ordinary least-squares regression models were used to examine the association between soft drinks consumption and child well-being by food security status. The reported $P$ values are two-sided and statistical significance was taken as $P<0 \cdot 05$. The analyses were conducted using the statistical software package Stata/MP version 13.1. Weighted and unweighted estimates provided similar results, so only the unweighted estimates are presented.

\section{Results}

\section{Sample characteristics}

About $43 \%$ of children in this sample had at least one serving of soft drinks on a given day. Summary statistics, including socio-economic and demographic characteristics, are presented in Table 1 by food security status. A higher proportion of food-insecure children (51.4 v. $41.2 \%)$ consumed soft drinks and had trouble sleeping at night $(30 \cdot 1 v \cdot 25 \cdot 0 \%)$. In addition, the SD of the mean 
Table 1 Descriptive statistics of children in the sample by food security status, Fragile Families and Child Wellbeing Study (n 2829)

\begin{tabular}{|c|c|c|c|}
\hline Variable & $\begin{array}{l}\text { Food } \\
\text { secure }\end{array}$ & $\begin{array}{c}\text { Food } \\
\text { insecure }\end{array}$ & $\begin{array}{c}\text { Significantly } \\
\text { different }\end{array}$ \\
\hline \multicolumn{4}{|l|}{ Daily soft drinks consumption (\%) } \\
\hline 0 & $58 \cdot 8$ & $48 \cdot 6$ & ** \\
\hline 1 & 24.7 & $26 \cdot 4$ & ** \\
\hline 2 & 9.4 & $12 \cdot 9$ & ** \\
\hline 3 & 4.0 & 6.5 & ** \\
\hline 4 or more & $3 \cdot 2$ & $5 \cdot 6$ & ** \\
\hline Child has trouble sleeping (\%) & $25 \cdot 0$ & $30 \cdot 1$ & ** \\
\hline Child is a girl (\%) & 48.9 & $44 \cdot 6$ & ** \\
\hline \multicolumn{4}{|l|}{ Mother's race (\%) } \\
\hline White & $22 \cdot 8$ & 14.7 & ** \\
\hline Black & $50 \cdot 2$ & $56 \cdot 6$ & ** \\
\hline Hispanic & $24 \cdot 2$ & $26 \cdot 0$ & ** \\
\hline Other & $2 \cdot 8$ & 2.7 & \\
\hline \multicolumn{4}{|l|}{ Mother's education at baseline (\%) } \\
\hline High-school dropout & $31 \cdot 3$ & $40 \cdot 4$ & ** \\
\hline High-school graduate & 30.5 & 34.0 & ** \\
\hline Some college & $26 \cdot 2$ & $21 \cdot 8$ & ** \\
\hline College graduate and beyond & $12 \cdot 0$ & 3.8 & $\star \star$ \\
\hline Mother employed (\%) & $61 \cdot 2$ & 53.5 & ** \\
\hline Income to poverty ratio & $2 \cdot 0$ & 1.0 & ** \\
\hline \multicolumn{4}{|l|}{ Mother's relationship with father (\%) } \\
\hline Married & $32 \cdot 6$ & 17.4 & ** \\
\hline Cohabitating & $13 \cdot 1$ & $12 \cdot 5$ & \\
\hline Non resident & $18 \cdot 0$ & $23 \cdot 7$ & ** \\
\hline Separated & $36 \cdot 3$ & $46 \cdot 5$ & ** \\
\hline Mother's social support (0-4) & 3.2 & 2.4 & ** \\
\hline Material hardship (0-5) & 0.9 & 1.9 & ** \\
\hline Receives food stamps (\%) & 39.8 & 64.1 & ** \\
\hline \multicolumn{4}{|l|}{ Parenting characteristics } \\
\hline Parenting stress $(1-4)$ & $2 \cdot 1$ & $2 \cdot 4$ & ** \\
\hline Maternal depression (\%) & $14 \cdot 0$ & $29 \cdot 7$ & ** \\
\hline Domestic violence (\%) & 0.6 & 1.3 & $\star \star$ \\
\hline Past drug or alcohol problems (\%) & $12 \cdot 2$ & $24 \cdot 8$ & ** \\
\hline Low birth weight (\%) & $9 \cdot 8$ & 11.8 & ** \\
\hline Mother smoked during pregnancy (\%) & 0.3 & 0.5 & ** \\
\hline Maternal self-control $(1-4)$ & 1.5 & 1.7 & ** \\
\hline Paternal self-control (1-4) & 1.7 & 1.8 & ** \\
\hline Number of observations & 2280 & 549 & \\
\hline
\end{tabular}

Significance levels: ${ }^{*} P<0.05,{ }^{*} P<0.01$.

sleep time was greater for food-insecure children than for food-secure children $(1.41 v .1 .24 \mathrm{~h})$. Food-insecure children had mothers who were more likely to be black (56.6 v. $50.2 \%)$ or Hispanic $(26 \cdot 0 v .24 \cdot 2 \%)$, have a high school degree or less $(74 \cdot 4 v \cdot 61 \cdot 8 \%)$, experience greater material hardship (1.9 $v \cdot 0 \cdot 9)$, have lower social support (2.4v.3.2) and more likely to participate in the Supplemental Nutrition Assistance Program (64.1 v. 39.8\%). Two-sample $t$ tests showed that most of the differences between the two groups were statistically significant.

\section{Association between soft drinks consumption and child behaviour problems}

Table 2 presents estimates from ordinary least-squares regression analyses. Regression models with soft drinks consumption as a continuous variable (not shown) were statistically significant. As a result, Table 2 presents estimates investigating potential dose-response relationships.

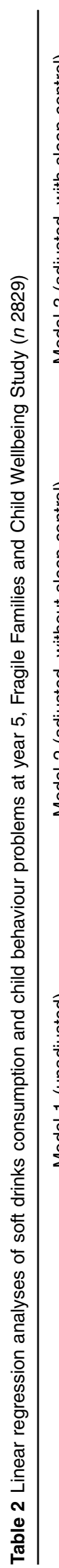

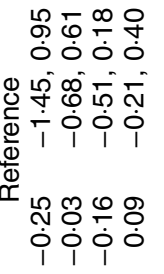

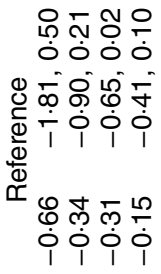

종 늉ํํ웅

ó0ं

هัด

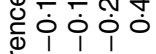

$\frac{\mathscr{4}}{\mathbb{\infty}}$

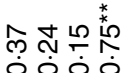

잉ำ

0ं0ல

๑ เกำ

o

离

幽

$\stackrel{0}{\infty} \stackrel{\infty}{\circ} \frac{0}{\circ}$

Oें⿰力口

๑

它

ब

\begin{tabular}{l}
$-60 \% 0$ \\
\hline 0 \\
0
\end{tabular}

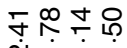

n- $1-4$

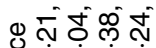

cólo

क्षे

这

웋ㅎํ 忞

-0́0

눙오윰

O००.

ญํํํํำ

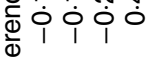

$\stackrel{\frac{\omega}{\infty}}{\square}$

咇 品둣

óó

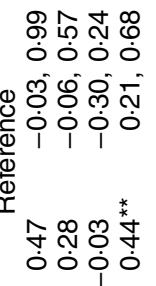

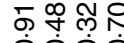

0

\&

엉잉

$\frac{\Phi}{\Phi}$

* ำ ㅇํㅇ

o0

유융ㅇㅇㅇ

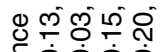

이ㅇㅟㅟㅇㅟ

迥

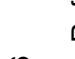

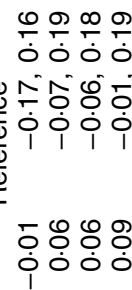

우웅웅

ن

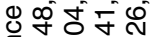

可识

\%

$\stackrel{\oplus}{\square}$

$*$

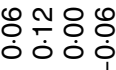

स

잉 웅

ญ

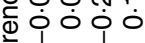

产

ธَ

ํํํํํำ

ญ

这的完

$\stackrel{\oplus}{\square}$

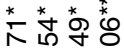

óㅇํㅇ

¿

बíó

(1)

ঙ

웅ํํ슨 는

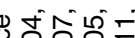

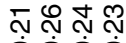

둥응

ช

*

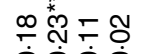

óóó

웅 $\stackrel{*}{\circ} \div \stackrel{*}{\leftarrow}$

0ं0்́

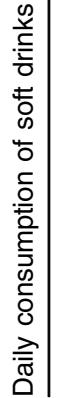


In each model, the estimates are presented for food-secure children and food-insecure children. In unadjusted models (Model 1, Table 2), soft drinks consumption was associated with child behaviour problems in all the measures $(P<0.05)$. For example, two servings of soft drinks daily increased aggressive behaviours by about 0.54 SD $(P<0.05)$, increased withdrawn behaviours by about $0.23 \mathrm{SD}(P<0.01)$ and increased attention problems by about $0.13 \mathrm{SD}(P<0.05)$ in food-secure children.

In adjusted models that included all control variables (Model 2, Table 2), adjusting for the covariates reduced the size of the coefficient of soft drinks consumption for all of the measures.

A test of interaction term between food insecurity and soft drinks consumption was statistically significant, showing that the association between soft drinks consumption and child behaviour problems differs by food security status. In other words, the negative impact of soft drinks consumption was greater for food-insecure children. The association of soft drinks and child behaviour problems was no longer statistically significant for food-secure children except for aggressive behaviours. This means that the association between soft drinks and child behaviour problems can be explained by all of the control variables (e.g. socio-economic status, demographic factors, parenting, etc.). Only children who consumed four or more soft drinks daily had a statistically significant higher risk of aggressive behaviours ( 0.77 SD, $P<0 \cdot 01)$.

Among food-insecure children, the risk of aggressive behaviours was statistically significant for children who consumed two (0.91 SD, $P<0.05)$ and four or more (0.87 SD, $P<0.01)$ soft drinks daily. Only children who consumed four or more soft drinks daily had a higher score on the withdrawn subscale ( 0.44 sD,$P<0 \cdot 01)$. Also, children who consumed one $(0.48$ SD, $P<0.05)$ and four or more $(0.49$ SD, $P<0.01)$ soft drinks daily had higher attention problems.

Model 3 in Table 2 estimates the same model as Model 2 and includes child sleep problems. For food-secure children, the association between soft drinks and child aggressive behaviours remained statistically significant for those who consumed four or more soft drinks daily. On the other hand, the association between soft drinks and child behaviour problems was no longer statistically significant for all of the other outcomes. This implies that sleep problems could be an important omitted factor and that soft drinks affect child behaviour problems through sleep disruption for food-insecure children.

\section{Discussion}

The negative consequences of soft drinks consumption go beyond physical health outcomes and can also affect the behaviour of children. In this sample of children in disadvantaged families, about $43 \%$ consumed one or more serving of soft drinks daily. Previous studies have found an association between soft drinks consumption and several measures of child well-being ${ }^{(6-8)}$. The current study shows that food insecurity and sleep disruption could help explain this association. Multivariate ordinary least-squares regression models showed an association between soft drinks and child behaviour problems. However, examining the association by food security status, the association between soft drinks consumption and child behaviour problems was no longer statistically significant for foodsecure children. This means that the negative association between soft drinks and child behaviour problems for food-secure children can be explained by the other control variables included in the study. On the other hand, soft drinks consumption was associated with greater child behaviour problems for food-insecure children, which may indicate that food insecurity could exacerbate child behaviour problems for those who consume soft drinks. In addition, children who consumed four or more soft drinks per day had more aggressive behaviours (0.87 SD, $P<0.01)$, scored higher on the withdrawn subscale (0.44 SD, $P<0.01)$ and had greater attention problems (0.49 SD, $P<0 \cdot 01)$. These associations were no longer statistically significant after accounting for sleep disruptions, indicating that the negative impacts of soft drinks consumption on child behaviour problems may be through sleep problems for food-insecure children.

One explanation for these findings could be that foodinsecure children are in poorer health and have higher risk of behaviour problems to begin with ${ }^{(14-16)}$. Given that food-insecure children have multiple nutrient deficiencies $^{(20,52)}$, soft drinks consumption could amplify the risk of behaviour problems for these children.

Healthier foods tend to be cost-prohibitive and thus inaccessible for low-income and food-insecure households ${ }^{(53)}$. There is a growing disparity in the price of nutrient-dense and lower-energy-density (unhealthy) foods ${ }^{(54,55)}$. As a result, these households are left with only energy-dense foods such as sugars, refined grains and fats that have little nutritional value ${ }^{(56)}$. These unhealthy diets may have long-term consequences as food-insecure adults are more likely to have poorer health, depression, and higher rates of diabetes and chronic diseases ${ }^{(57-60)}$.

Another explanation could be related to the composition of soft drinks, which have large amounts of sugar and caffeine. Given that the association was no longer statistically significant after accounting for sleep problems, it is possible that the consumption of soft drinks in children could disrupt their sleep patterns, leading to behaviour problems. These findings are consistent with studies showing an association between soft drinks consumption and sleep disruptions ${ }^{(29-21)}$ and with those that find an association between sleep disruptions and child behaviour problems ${ }^{(26-28)}$. However, these findings 
should be interpreted cautiously given the imprecision of the soft drinks measure (size, frequency and type).

Special attention should be given to the fact that controlling for sleep made the associations statistically insignificant for food-insecure children. These children not only consume soft drinks more often, but are also at greater disadvantage than food-secure children.

The present study has several limitations. First, the soft drinks consumption measure asks the parent about the number of servings, the size of which is not defined. Therefore it is unclear whether the parent is reporting the consumption of a can or something else. However, these measurement errors would likely only increase the SE as there is no reason to think that they may be correlated with behaviour problems. In addition, the measure does not distinguish between children who do not consume any soft drinks and those who consume only a few servings per week, hence less than one per day. Second, the type of soft drinks consumed is not specified. For example, regular and diet soft drinks are distinct and may have different impacts. It is then not possible to determine whether the results could be attributed to sugar, caffeine, or both. Lastly, the sample is representative of non-marital births in large cities only, which reduces the generalizability of the results.

\section{Conclusions}

In the current study of children in fragile families, soft drinks consumption was associated with greater child behaviour problems. However, when examining by food security status, the association remained statistically significant only for food-insecure children. This association became statistically insignificant for food-insecure children after accounting for sleep patterns.

The study findings indicate that food insecurity may be linked to unhealthy behaviours such as soft drinks consumption and sleep deprivation, which are risk factors for behaviour problems in children. These risk factors disproportionally affect low-income households who are more likely to be food insecure and consume more soft drinks than higher-income households ${ }^{(61)}$.

One important finding of the study points to sleep disruption being a potentially important factor that explains the association between soft drinks consumption and behaviour problems for food-insecure children. It may be that soft drinks consumption is a secondary issue while poor and insufficient sleep may be the main issue at play. Insufficient sleep among children seems to be an important problem worldwide as children's sleep duration has declined steadily over time ${ }^{(62)}$. In addition, given that the association between soft drinks consumption and child behaviour problems was entirely mediated by sleep disruption for food-insecure children only in our crosssectional analysis, additional research (especially longitudinal) is needed to provide further insight into this relationship. For example, do these negative associations persist or can they be reversed?

Additional research is also needed with more precise measures of soft drinks consumption (in terms of size of drink, frequency of consumption and type of drink) to determine whether the risk of behaviour problems in children is similar or different between those who do not consume soft drinks at all and those who consume fewer than one serving daily. Also, future research should determine whether these findings are generalizable to all young children.

\section{Acknowledgements}

Financial support: Research reported in this publication was supported by the Eunice Kennedy Shriver National Institute of Child Health and Human Development (NICHD) of the National Institutes of Health (award numbers R01HD36916, R01HD39135 and R01HD40421), as well as a consortium of private foundations. The content is solely the responsibility of the author and does not necessarily represent the official views of the National Institutes of Health. Conflict of interest: None. Authorship: C.K. was responsible for the whole manuscript. Ethics of buman subject participation: In accordance with the Declaration of Helsinki, all families provided informed consent before participating in the study. Because the Fragile Families data set is publicly available, institutional review board approval was not needed.

\section{References}

1. Statista (2015) Per capita consumption of soft drinks in the United States from 2000 to 2014 (in gallons). http://www. statista.com/statistics/306836/us-per-capita-consumption-ofsoft-drinks/ (accessed November 2015).

2. Wang YC, Bleich SN \& Gortmaker SL (2008) Increasing caloric contribution from sugar-sweetened beverages and $100 \%$ fruit juices among US children and adolescents, 1988-2004. Pediatrics 121, e1604-e1614.

3. Kit BK, Fakhouri TH, Park S et al. (2013) Trends in sugar-sweetened beverage consumption among youth and adults in the United States: 1999-2010. Am J Clin Nutr 98, 180-188.

4. Fung TT, Malik V, Rexrode KM et al. (2009) Sweetened beverage consumption and risk of coronary heart disease in women. Am J Clin Nutr 89, 1037-1042.

5. Vartanian LR, Schwartz MB \& Brownell KD (2007) Effects of soft drink consumption on nutrition and health: a systematic review and meta-analysis. Am J Public Health 97, 667-675.

6. DeChristopher LR, Uribarri J \& Tucker KL (2016) Intakes of apple juice, fruit drinks and soda are associated with prevalent asthma in US children aged 2-9 years. Public Health Nutr 19, 123-130.

7. Lien L, Lien N, Heyerdahl S et al. (2006) Consumption of soft drinks and hyperactivity, mental distress, and conduct problems among adolescents in Oslo, Norway. Am J Public Health 96, 1815-1820. 
8. Suglia SF, Solnick S \& Hemenway D (2013) Soft drinks consumption is associated with behavior problems in 5-year-olds. J Pediatr 163, 1323-1328.

9. Haapalahti M, Mykkänen H, Tikkanen S et al. (2003) Meal patterns and food use in 10- to 11-year-old Finnish children. Public Health Nutr 6, 365-370.

10. Han E \& Powell LM (2013) Consumption patterns of sugarsweetened beverages in the United States. J Acad Nutr Diet 113, 43-53.

11. Ogden CK, Kit BK, Carroll MD et al. (2011) Consumption of Sugar Drinks in the United States, 2005-2008. NCHS Data Brief no. 71. Hyattsville, MD: National Center for Health Statistics.

12. Vereecken CA, Inchley J, Subramanian SV et al. (2005) The relative influence of individual and contextual socioeconomic status on consumption of fruit and soft drinks among adolescents in Europe. Eur J Public Health 15, 224-232.

13. US Department of Agriculture (2016) Food Security in the US. http://www.ers.usda.gov/topics/food-nutrition-assistance/ food-security-in-the-us.aspx (accessed May 2016).

14. Huang J, Oshima KMM \& Kim Y (2010) Does food insecurity affect parental characteristics and child behavior? Testing mediation effects. Soc Serv Rev 84, 381-401.

15. Slack KS \& Yoo J (2005) Food hardship and child behavior problems among low income children. Soc Serv Rev 79 511-536.

16. Howard LL (2011) Does food insecurity at home affect noncognitive performance at school? A longitudinal analysis of elementary student classroom behavior. Econ Educ Rev 30, $157-176$.

17. Liu J, Raine A, Venables PH et al. (2004) Malnutrition at age 3 years and externalizng behavior problems at ages 8, 11, and 17 years. Am J Psychiatry 161, 2005-2013.

18. Benton J (2008) The influence of children's diet on their cognition and behavior. Eur J Nutr 47, 25-37.

19. Coleman-Jensen A, Rabbitt M, Gregory C et al. (2015) Household Food Security in the United States in 2014. Economic Research Report no. ERR-194. Washington, DC: US Department of Agriculture, Economic Research Service.

20. Kirkpatrick SI \& Tarasuk V (2008) Food insecurity is associated with nutrient inadequacies among Canadian adults and adolescents. J Nutr 138, 604-612.

21. Tarasuk V \& Beaton GH (1999) Household food insecurity and hunger among families using food banks. Can J Public Health 90, 109-113.

22. Cunningham T, Barradas D, Rosenberg K et al. (2012) Is maternal food security a predictor of food and drink intake among toddlers in Oregon? Matern Child Health J 16, 339-346.

23. Garnett BR, Rosenberg KD \& Morris DS (2013) Consumption of soda and other sugar-sweetened beverages by 2-year-olds: findings from a population-based survey. Public Health Nutr 16, 1760-1767.

24. Pabayo R, Spence JC, Cutumisu N et al. (2012) Sociodemographic, behavioural and environmental correlates of sweetened beverage consumption among preschool children. Public Health Nutr 15, 1338-1346.

25. Larson NI, Story MT \& Nelson MC (2009) Neighborhood environments: disparities in access to healthy foods in the US. Am J Prev Med 36, 74-81.e10.

26. Lavigne JV, Arend R, Rosenbaum D et al. (1999) Sleep and behavior problems among preschoolers. J Dev Behav Pediatr 20, 164-169.

27. Sadeh A, Gruber R \& Raviv A (2002) Sleep, neurobehavioral functioning, and behavior problems in school-age children. Child Dev 73, 405-417.

28. Stein MA, Mendelsohn J \& Obermeyer WH (2001) Sleep and behavior problems in school-aged children. Pediatrics 107, e60.
29. Collison KS, Zaidi MZ, Subhani SN et al. (2010) Sugarsweetened carbonated beverage consumption correlates with BMI, waist circumference, and poor dietary choices in school children. BMC Public Health 10, 1.

30. Park S, Sherry B, Foti K et al. (2012) Self-reported academic grades and other correlates of sugar-sweetened soda intake among US adolescents. J Acad Nutr Diet 112, 125-131.

31. Warzak WJ, Evans S, Floress MT et al. (2011) Caffeine consumption in young children. J Pediatr 158, 508-509.

32. Pollak CP \& Bright D (2003) Caffeine consumption and weekly sleep patterns in US seventh-, eighth-, and ninthgraders. Pediatrics 111, 42-46.

33. Roehrs T \& Roth T (2008) Caffeine: sleep and daytime sleepiness. Sleep Med Rev 12, 153-162.

34. Temple JL (2009) Caffeine use in children: what we know, what we have left to learn, and why we should worry. Neurosci Biobehav Rev 33, 793-806.

35. St-Onge M, Roberts A, Shechter A et al. (2016) Fiber and saturated fat are associated with sleep arousals and slow wave sleep. I Clin Sleep Med 12, 19-24.

36. Ding M, Keiley MK \& Garza KB (2015) Food insecurity is associated with poor sleep outcomes among US adults. J Nutr 145, 615-621.

37. Reichman NE, Teitler JO, Garfinkel I et al. (2001) Fragile families: sample and design. Child Youth Serv Rev 23, 303-326.

38. Geller A, Garfinkel I \& Western B (2011) Paternal incarceration and support for children in fragile families. Demography 48, 25-47.

39. Högnäs RS \& Carlson MJ (2010) Intergenerational relationships and union stability in fragile families. J Marriage Fam 72, 1220-1233.

40. Institute of Medicine, National Research Council (2014) The National Children's Study 2014: An Assessment [GJ Duncan, NJ Kirkendall and CF Citro, editors]. Washington, DC: The National Academies Press.

41. Achenbach TM \& Rescola LA (2000) Child behavior checklist for ages $1 \frac{1}{2}-5$; language development survey; caregiver-teacher report form. In Manual for the ASEBA Preschool Forms \& Profiles: An Integrated System of MultiInformant Assessment. Burlington, VT: University of Vermont, Research Center for Children, Youth, and Families.

42. Achenbach TM (1991) Manual for the Child Behavior Checklist/4-18 and 1991 Profile. Burlington, VT: University of Vermont, Department of Psychiatry.

43. Corman H, Noonan K \& Reichman NE (2014) Effects of infant health on family food insecurity: evidence from two US birth cohort studies. Soc Sci Med 123, 18-25.

44. Cox R \& Wallace S (2016) Identifying the link between food security and incarceration. South Econ J 82, 1062-1077.

45. Kimbro RT \& Denney JT (2015) Transitions into food insecurity associated with behavioral problems and worse overall health among children. Health Aff (Millwood) 34, 1949-1955.

46. King C (2016) Food insecurity and housing instability in vulnerable families. Rev Econ Househ 1-19, DOI: 10.1007/ s11150-016-9335-z.

47. Turney K (2015) Paternal incarceration and children's food insecurity: a consideration of variation and mechanisms. Soc Serv Rev 89, 335-367.

48. Kessler RC, Andrews G, Mroczek D et al. (1998) The World Health Organization composite international diagnostic interview short-form (CIDI-SF). Int J Methods Psychiatr Res 7, 171-185.

49. Von Hippel PT (2007) Regression with missing Ys: an improved strategy for analyzing multiply imputed data. Sociol Methodol 37, 83-117.

50. Royston P (2004) Multiple imputation of missing values. Stata J 4, 227-241. 
51. Royston P (2005) Multiple imputation of missing values: update of ice. Stata J 55, 527-536.

52. Tarasuk VS (2001) Household food insecurity with hunger is associated with women's food intakes, health and household circumstances. J Nutr 131, 2670-2676.

53. Monsivais P \& Drewnowski A (2009) Lower-energy-density diets are associated with higher monetary costs per kilocalorie and are consumed by women of higher socioeconomic status. J Am Diet Assoc 109, 814-822.

54. Monsivais P, McLain J \& Drewnowski A (2010) The rising disparity in the price of healthful foods: 2004-2008. Food Policy 35, 514-520.

55. Monsivais P \& Drewnowski A (2007) The rising cost of low-energy-density foods. J Am Diet Assoc 107, 2071-2076.

56. Drewnowski A \& Specter S (2004) Poverty and obesity: the role of energy density and energy costs. Am J Clin Nutr 79, 6-16.

57. Leung CW, Epel ES, Willett WC et al. (2015) Household food insecurity is positively associated with depression among low-income supplemental nutrition assistance program participants and income-eligible nonparticipants. $J$ Nutr 145, 622-627.

58. Seligman H, Bindman A, Vittinghoff E et al. (2007) Food insecurity is associated with diabetes mellitus: results from the National Health Examination and Nutrition Examination Survey (NHANES) 1999-2002. J Gen Intern Med 22, 1018-1023.

59. Seligman HK, Laraia BA \& Kushel MB (2010) Food insecurity is associated with chronic disease among low-income NHANES participants. J Nutr 140, 304-310.

60. Stuff JE, Casey PH, Szeto KL et al. (2004) Household food insecurity is associated with adult health status. J Nutr 134, 2330-2335.

61. Finkelstein E, Zhen C, Nonnemaker J et al. (2010) Impact of targeted beverage taxes on higher- and lower-income households. Arch Intern Med 170, 2028-2034.

62. Matricciani L, Olds T \& Petkov J (2012) In search of lost sleep: secular trends in the sleep time of school-aged children and adolescents. Sleep Med Rev 16, 203-211. 